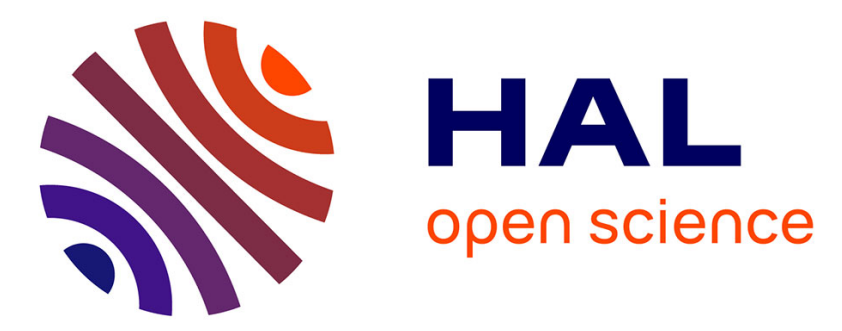

\title{
Frequency Control Using V2G and Synchronous Power Controller based HVDC Links in Presence of Wind and PV Units
}

Ritu Raj Shrivastwa, Ahmad Hably, Sanjoy Debbarma, Seddik Bacha

\section{To cite this version:}

Ritu Raj Shrivastwa, Ahmad Hably, Sanjoy Debbarma, Seddik Bacha. Frequency Control Using V2G and Synchronous Power Controller based HVDC Links in Presence of Wind and PV Units. IECON 2018 - 44th Annual Conference of the IEEE Industrial Electronics Society, Oct 2018, Washington, DC, United States. hal-01895352

\section{HAL Id: hal-01895352 \\ https://hal.science/hal-01895352}

Submitted on 15 Oct 2018

HAL is a multi-disciplinary open access archive for the deposit and dissemination of scientific research documents, whether they are published or not. The documents may come from teaching and research institutions in France or abroad, or from public or private research centers.
L'archive ouverte pluridisciplinaire HAL, est destinée au dépôt et à la diffusion de documents scientifiques de niveau recherche, publiés ou non, émanant des établissements d'enseignement et de recherche français ou étrangers, des laboratoires publics ou privés. 


\title{
Frequency Control Using V2G and Synchronous Power Controller based HVDC Links in Presence of Wind and PV Units
}

\author{
Ritu Raj Shrivastwa, Ahmad Hably, Sanjoy Debbarma *, Seddik Bacha \\ Univ. Grenoble Alpes, CNRS, \\ Grenoble INP, G2elab, GIPSA-lab, \\ 38000 Grenoble, France. \\ ritu-raj.shrivastwa@grenoble-inp.org \\ * National Institute of Technology Meghalaya, Shillong, India
}

\begin{abstract}
The world is shifting towards Renewable Energy Sources (RES) to meet the increasing demand. With proportionally high penetration of RES, the inertia of the grid tends to fall due to the incapability of these sources to participate in control mechanism. Also, due to the indeterminacy in the generation pattern, they tend to feed small signal disturbances in the grid due to the imbalance of generation and demand, which affects the frequency stability. In this paper, the affect of inertia emulation (IE) in the grid is presented to mitigate the small signal disturbances caused due to the change in load or due to the penetration of the RES. This work has considered Electric Vehicles for the application of vehicle to grid (V2G) towards frequency control. A cooperative control method, with V2G and synchronous power controller (SPC) based HVDC links, has been proposed towards the control of the fluctuations and a considerable decrease in the deviations have been observed. Several case studies are conducted and the results are presented to proof the concept.

Index Terms-LFC, V2G, SPC based HVDC links, Inertia emulation, Renewable Energy Sources
\end{abstract}

\section{INTRODUCTION}

With the growing concerns of sustainable and environmental friendly technologies, more and more shift from the use of fossil fuel based power generating units is observed. However, more number of Renewable Energy Sources (RES) are being deployed to the conventional grids to meet the increasing demand of the population. But the key hurdles associated with the penetration of the RES is their intermittancy of production. Due to the uncontrollability in the generation from these sources, there is always a threat to the supply demand balance which results in the the frequency excursions from the mean value and large number of electrical storage may be required to overcome the deviations [1]. In context of the increasing penetration of these sources, the overall inertia of the grid also tends to reduce. Thus, there is a need to explore ways and appliances to emulate inertia in the grid. In presence of RES and the power electronic converters, inevitably loss of inertia in the grid tends to introduce the risk of instability with the associated changing load demands. Also, the traditional primary and secondary controls provided by the synchronous generators may have to suffer from rapid changes which may result into the mechanical wear and tear of these devices. Many countries have adopted high voltage direct current (HVDC) lines due to their services in frequency support, bidirectional control and damping of the power oscillations [2] - [3]. Thus, in many applications, the recent trends constitute the use of high voltage alternating current (HVAC) and HVDC lines running parallel to each other. However, too many use of power electronic converters alongside the RES reduces the grid inertia and IE hence becomes a major requirement as discussed by many authors as in [4] and [5]. In [6], inertia emulation has been exercised through the the use of derivative of the frequency signal for HVDC systems in actuating the stored energy of converter components towards the frequency regulation. But the proposal as in [6] is highly prone to the external noises and may be a threat to system stability. Overcoming this problem with the use of synchronous power controller (SPC) in [5] and [7], to emulate inertia in the grid, authors have proposed extraction of power from the converter stations for load frequency control (LFC).

With the paradigm shift from the centralized generation and vertical control to the distribution generation and horizontal control, entire power system is seemingly undergoing a massive change in the infrastructure and control strategies. In the studies carried out, consideration of synchronous and non-synchronous units is unavailable. In this work, nonsynchronous units such as wind and photo-voltaic (PV) are considered in the areas with high proportion of share in the generation. Also, DC links alone cannot suffice the need of inertia emulation in the grid due to the limitations in the available power. However, use of fixed or mobile storage such as Electric Vehicles (EVs) can be considered as an effective way of mitigating the frequency excursions by increasing the control of the grid sources [8]. EVs can participate in both primary frequency control (PFC) and in secondary control through V2G infrastructure [9].

In this work, a cooperative infrastructure between the V2G and the SPC based HVDC links has been proposed to mitigate the frequency excursions caused by the presence of nonsynchronous units and the change in loads. Also, several case studies have been carried out and compared to observe differences in the behavior of the system in presence and absence of 
the non-synchronous sources and SPC based HVDC links. The rest of the paper is organized into three sections with section II defining the modeling of the components and section III elaborating the results obtained in different cases considered. The paper ends with some conclusions in the last section IV.

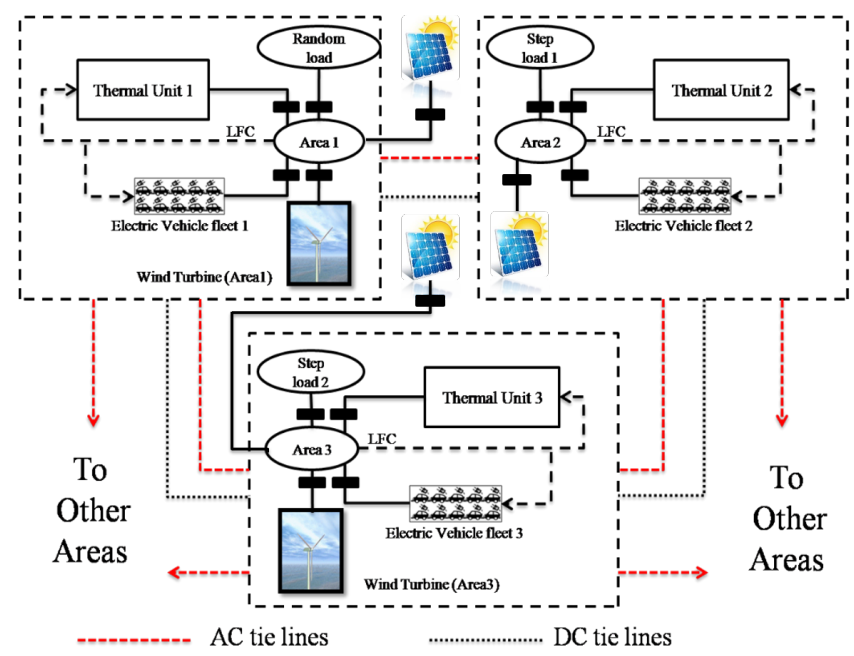

Fig. 1: Schematics of the 3 area system considered for test.

\section{MODELling OF THE SYSTEM UNDER TEST}

A. Designing of the three area systems with $V 2 G$ and generation sources i.e. wind and $P V$

A three area model for LFC with different sources and loads has been considered for the test as schematically presented in fig. 1. The values of time constants of various components such as governers, turbines and reheaters are procured from the contributions [10] and [11]. A high penetration of wind is considered in the areas 1 and 3 of which the nature and model is as given in fig. 2 and 3.

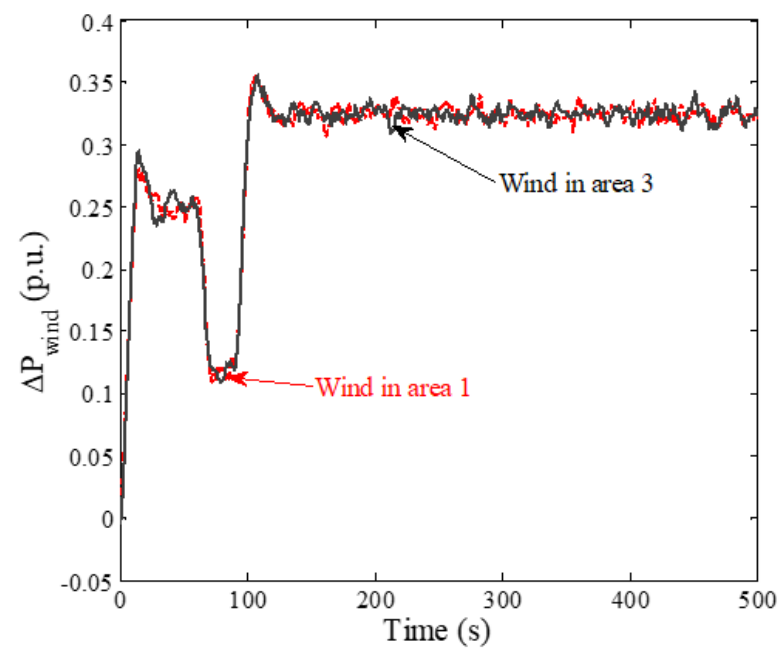

Fig. 2: Nature of the wind power output fed in areas 1 and 3.

The wind turbine model considered in the modelling has pitch control with the hydraulic pitch actuator and also a

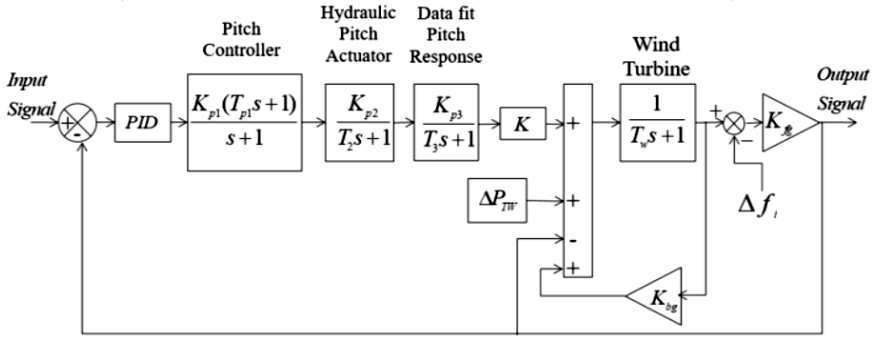

Fig. 3: Wind turbine model [12], [13].

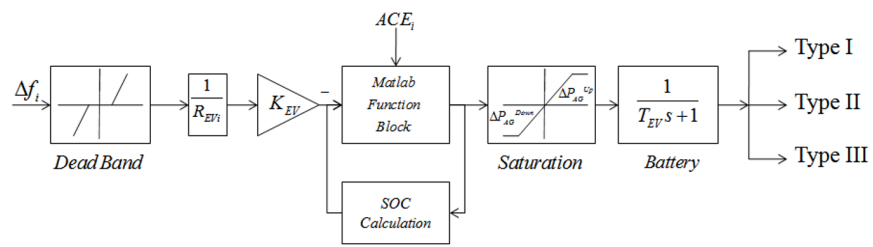

Fig. 4: Electric Vehicle model [12], [13].

model for the wind turbine. Entire modeling is done through the use of the corresponding transfer functions. For detailed description of the components [12] and [13] can be referred.

Number of EV users around the world is increasing at a great pace. With the non-scheduled increasing charging demands of the EVs, a threat is posed on the grid stability due to intermittent charging behaviors varying with every owner [14]. Problems such as frequency fluctuations or voltage dip may occur in the grid due to the unscheduled charging [15]. Thus, in order to obtain a sustainable stability in the system, the charging of EVs should be monitored and smartly scheduled [16]. A method similar to balanced SOC based EV charging and discharging is used in the modeling and control. However, proposal of using both frequency deviation signal and the area control error (ACE) signal is used for the control method. Determination of the charging and discharging is done based on the deviation of frequency below and above the rated value respectively. It is evident that in the primary frequency control (PFC) use of frequency deviation is considered for determining the charging and discharging, however, in the case of secondary frequency control (SFC) ACE signal is to be used for frequency regulation. A model of the EV used in the control is as represented as in fig 4 where the types of EVs may refer to the electric vehicles with different behaviors based on the owners referring to the level of SOC or to the level of SOC the owners wish to charge or discharge the EV towards frequency regulation. Mathematically, it can be represented as in equation 1 and equation 2.

$$
P_{E V i}= \begin{cases}K_{c} * \Delta f & \text { if } \Delta f>0 \\ K_{d} * \Delta f & \text { if } \Delta f<0 \\ \left|P_{A G}^{\min }\right| & \text { if }\left|K_{c} * \Delta f\right| \leq P_{A G}^{\min } \\ P_{A G}^{\max } & \text { if } K_{d} * \Delta f \leq P_{A G}^{\max }\end{cases}
$$




$$
P_{E V i}= \begin{cases}K_{c} * A C E & \text { if } A C E>0 \\ K_{d} * A C E f & \text { if } A C E<0 \\ \left|P_{A G}^{\min }\right| & \text { if }\left|K_{c} * A C E\right| \leq P_{A G}^{\min } \\ P_{A G}^{\max } & \text { if } K_{d} * A C E \leq P_{A G}^{\max }\end{cases}
$$

Where $P_{E V i}$ is the output power of the $i^{t h} \mathrm{~V} 2 \mathrm{G}$ fleet and $P_{A G}^{\max }$ and $P_{A G}^{\min }$ are the maximum and the minimum power that can be dispensed from the fleet. $K_{c}$ and $K_{d}$ represent the charging and discharging coefficients.

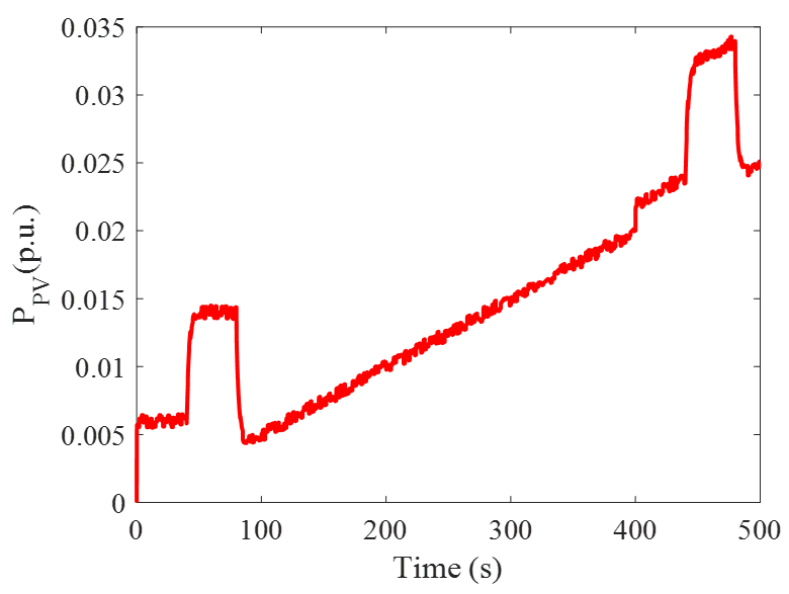

Fig. 5: Nature of the Solar Power fed to the areas.

Since solar is an intermittent source of power, a random pattern of generation with some steep fluctuations is taken into consideration for the test in worst situations. The graph in 5 represents the solar power fed to the grid in all the three areas. A complete model with the renewable sources, thermal generator, loads and HVDC with HVAC links is depicted in fig. 6 .

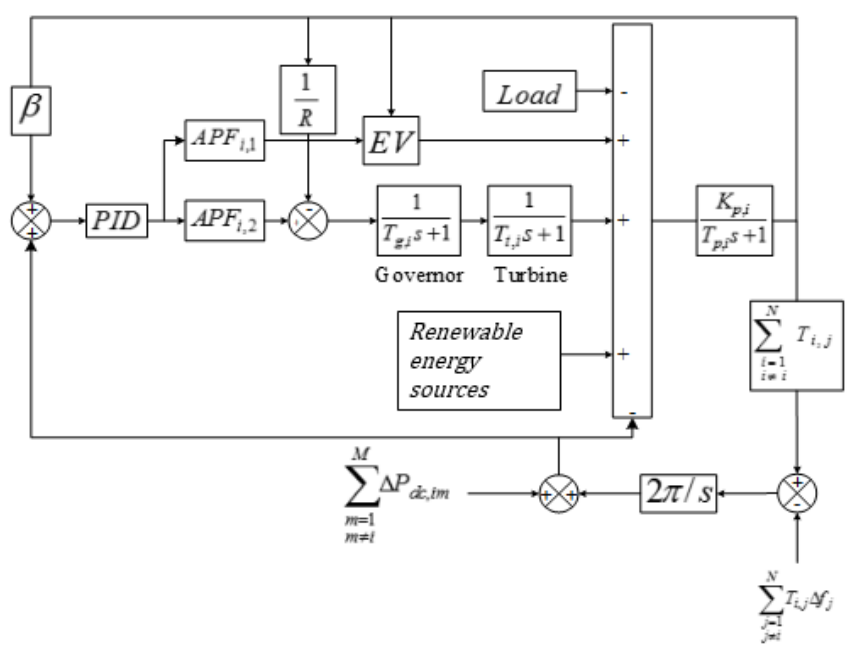

Fig. 6: Model of the $i_{t h}$ area with EVs, HVDC links and Energy sources.

\section{B. HVDC links with SPC for inertia emulation}

In this section, we discuss the modeling of the HVDC links using the concept of the SPC. Basically, it refers to the control of the Voltage Sources Controllers (VSCs) of the HVDC links via active power loop and virtual admittance (VA) [17]. With the HVDC links running parallel to the HVAC lines, the dc power deviation between area $\mathrm{i}$ and area $\mathrm{j}$ can be given as in equation 3 .

$$
\Delta P_{d c, i-j}(s)=\frac{K_{d c, i}}{1+s T_{d c, i}} \Delta E_{d c, i}(s)
$$

Where $\Delta E_{d c, i}, K_{d c, i}$, and $T_{d c, i}$ are the control error as given in 4, the feedback gain of the HVDC tie-line and time constant of the HVDC tie-line respectively.

$$
\Delta E_{d c, i}(s)=\left[K_{f i} \Delta f_{i}(s)+K_{a c} \Delta P_{t i e, i-j}(s)+K_{f j} \Delta f_{j}(s)\right]
$$

In the SPC loop of the HVDC, the capacitors between the two converter stations in DC link can be modelled in the topology of the converter [7]. Since SPC does not posses infinite storage of power, so in case of bigger requirements more number of storage can be used alongside to fulfill the requirements. The active SPC loop as in fig. 7 used in the work consists of two blocks namely electromechanical and virtual admittance. The rational behavior of the power loop controller (PLC) can be represented as in equation 5.

$$
P L C(s)=\frac{\omega_{n}^{2} / P_{\text {Active }}}{s+2 \zeta \omega_{n}}
$$

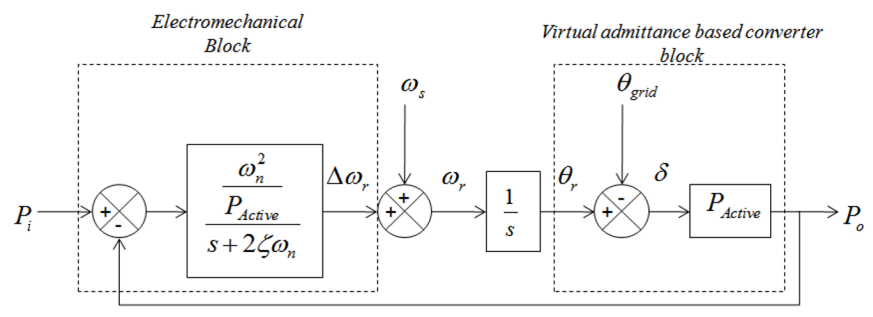

Fig. 7: Active SPC loop for HVDC systems.

Where $P_{i}, P_{o}, \omega_{n}, \zeta$ and $P_{\text {Active }}$ are the input power of converter, output power of the converter, natural frequency, damping factor and the maximum delivered active power respectively. The combination of the error in the rotor frequency $\Delta \omega_{r}$ and the frequency corresponding to the synchronous speed of grid $\omega_{s}$ gives the virtual rotor frequency $\omega_{r}$ from which the load angle $\delta$ is achieved by integrating $\omega_{r}$ and then subtracting it with the grid voltage angle which eventually gives the final output power to the grid as in equation 6 .

$$
P_{o}=P_{\text {Active }} * \delta
$$

Where $P_{\text {Active }}$ is a ratio of the product between the electromotive force $(\mathrm{E})$ and grid voltage $(\mathrm{V})$ to the virtual admittance $(\mathrm{X})$ 
and the thus the final transfer function model of the systems stands out as in equation 7.

$$
\frac{P_{o}}{P_{i}}=\frac{\omega_{n}^{2}}{s^{2}+2 \zeta \omega_{n} s+\omega_{n}^{2}}
$$

with $\omega_{n}=\sqrt{\frac{P_{\text {Active }}}{j \omega_{s}}}$ and $\zeta=\frac{D}{2 \sqrt{P_{\text {Active }} J \omega_{s}}}$ where the values of $\mathrm{D}$ and $\mathrm{J}$ correspond to the damping coefficient and the moment of the inertia of the system and can be tuned to obtain the desired output. Thus the control error can be finally rewritten as $\Delta E_{S P C, d c i}(s)=\left[K_{S P C, f_{i}} \Delta f_{i}(s)+K_{S P C, f j} \Delta f_{j}(s)+\right.$ $\left.K_{S P C, a c} \Delta P_{t i e, i-j}\right]$. Here, $\Delta E_{S P C, d c i}$ goes in as an input to the controller and $\triangle P_{S P C, d c, i-j}$ is obtained as the output and similarly for multiple links the corresponding output would be $\sum_{i=1, i \neq j}^{k}=\Delta P_{S P C, d c, i-j}$, where, $k$ represents the number of the stations employed in the network.

\section{SimULATIONS AND ANALYSIS}

To prove the concept and find out how HVDC links are affecting the grid control, a three interconnected area system is modelled with thermal power and EVs and solar power being fed in each of the areas. However, wind power is fed to areas 1 and 3. Successively, all the three areas are connected with the HVDC links as well in coordination with the AC tie lines. Focus has been laid to investigate the role of the SPC based HVDC links in mitigating the effect of the penetration of the renewable sources in the grid. Simulations are carried out in three different scenarios as listed below:

1) Case I: Here, a simple power system with the thermal unit and the EVs in a V2G configuration are considered for the analysis of grid frequency control and step loads of 0.01 p.u. are provided to the areas 2 and 3 with a random loading condition being provided to area 1 .

2) Case II: In this case, in addition to the system in case $\mathrm{I}$, the renewable sources are fed to the system and then the response of the system is obtained and observed. High wind power penetration is considered and low PV penetration is considered as depicted in the figures 2 and 5 respectively. Main focus in this case is to observe the effect of the RES on the grid as how the change in frequency occurs and also it is evident that with the same loading, how the overall inertia of the grid is affected.

3) Case III: Finally the SPC based HVDC links are utilized to increase the inertia and are used in coordination to RES and V2G configuration of EVs to investigate the effectiveness of this combination of sources and methods in mitigating the frequency deviations in the network occurring due to reduced inertia under the same loading condition.

In accordance to the above mentioned cases, a comparative study was carried out to analyze the behavior of the system in all the three situations through the deviations in the frequency and changes in the tie line power exchanges in and between the areas respectively as presented in the figures 8 and 9 . With increased generation in the areas and also with more available

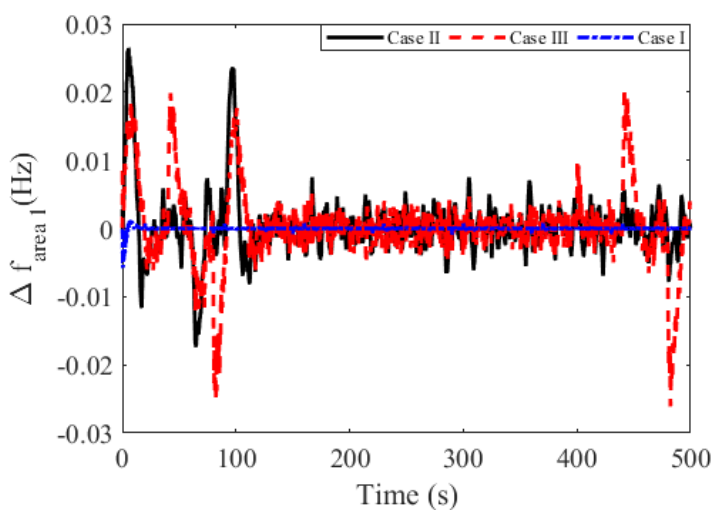

(a)

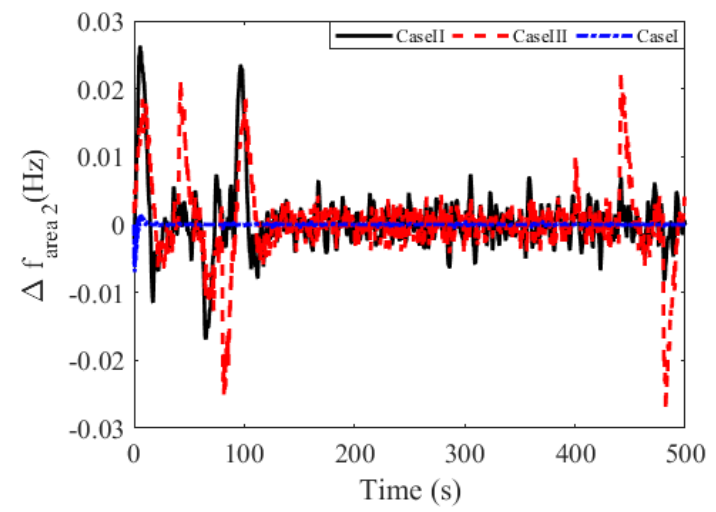

(b)

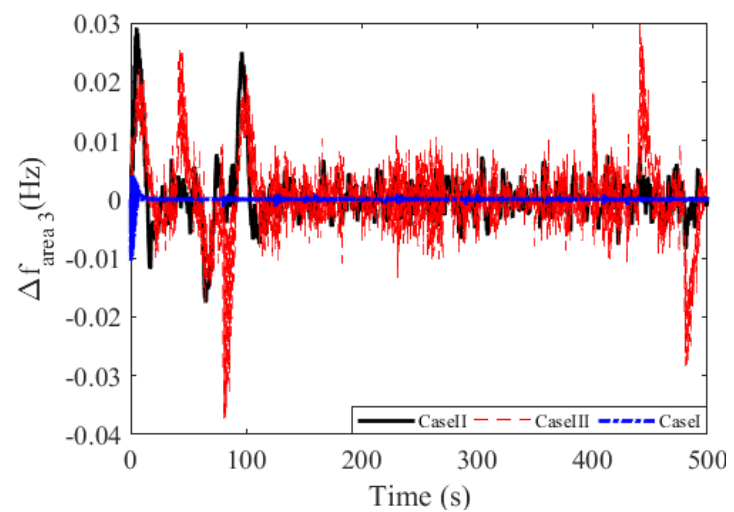

(c)

Fig. 8: Dynamic response of the frequency in all the three areas represented in (a) for area 1 (b) for area 2 and (c) for area 3 respectively.

control for the deviations the tie line power exchange among the areas reduce as seen in figure 9.

From the above comparison of the frequency deviations in all the three scenarios it is very evident that the excursions increase with the penetration of the renewable sources due to their incapability to participate in the load frequency control. As observed in Case I, the fluctuations are minimum as the thermal unit and the EVs are sufficient to mitigate and meet the 
requirements. However, in Case II the scenario changes with RES being fed to the areas which besides reducing the inertia of the grid, also injects more deviation in the frequency due to changes in the power generation pattern of the sources. But after the load settles to a new value, the system adapts and the generation matches the requirement by reaching a new value. With the penetration of the RES in the grid, the grid inertia falls and thus to achieve better response inertia emulation through reliable sources becomes a very important tool. Thus, with the use of SPC based HVDC links inertia is emulated alongside the other sources used for the mitigation process. In the third case, HVDC links help in fast response of the system towards reducing the peaks of the deviations through responding simultaneously with the other sources aiding them to meet the fluctuating demand as we can see in figure 10 . To reduce the ACE to zero through the secondary control, a PID controller is used which is tuned using Cuckoo Search Algorithm (CSA) through the minimization of the Integral time absolute error (ITAE). CSA is found to be very efficient in solving non linear optimization or complex optimization problems [18] - [19]. Also, it is evident that with introduction of more number of RES in the grid, the generation of the fossil fuel based generation units can be reduced considerably. Though the time constants of all of the generation units are different but the responses from the storage devices like EVs and SPC based DC links can be very effective and fast in response in order to meet the fluctuating demands. It can be debated that if the frequency deviations are met near to the sources of generation of these deviations, then the stress on the power generating sources can be drastically reduced and the life span of the latter can be improved considerably.

\section{CONCLUSION AND FUTURE WORK}

With increased control of the components in the grids, it is becoming more and more feasible to implement ideas like the use of SPC based HVDC links in coordination with the flexible devices like EVs and other storage systems in order to meet the fluctuating demands of the grid. In this work, we see how effectively the frequency regulation is achieved. EVs being considered as mobile storage can be used towards the demand side management in the future power grids with the V2G technology through bi-directional converters. Also, energy markets will see a new shift from the existing model giving openings for the smaller players and prosumers to participate in energy trading. Also, different community based structures can be developed with local control methods through the compensation of the frequency deviations locally through the locally available RES such that the deviations are not transmitted to the conventional generators. Challenges related to the scheduled charging and discharging of EVs can be studied in coordination to the SPC based HVDC links as the links do not posses infinite power and cannot alone mitigate the error. Also, studies based on realistic data can be performed for any specific grid to understand the effectiveness of the concept.

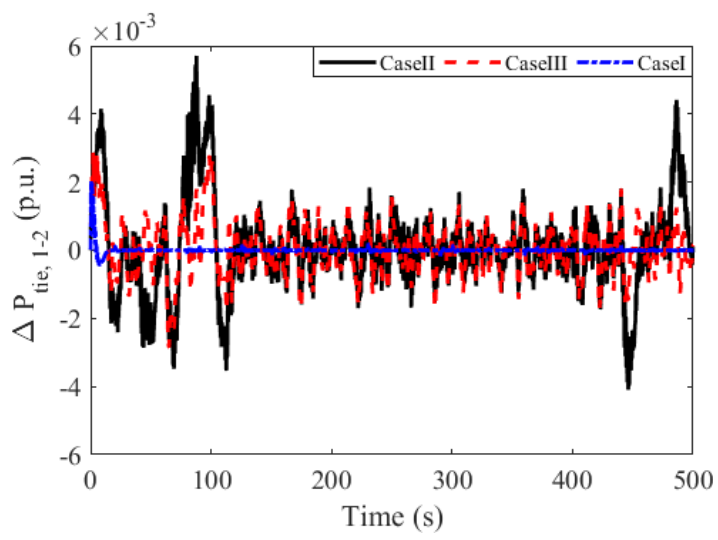

(a)

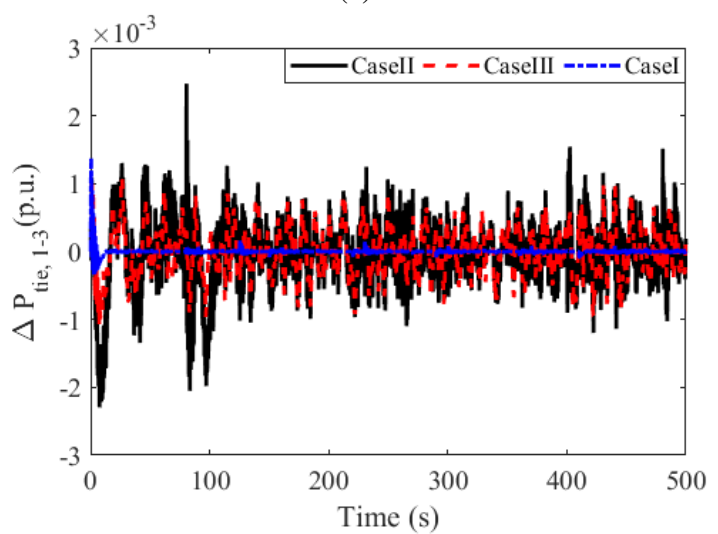

(b)

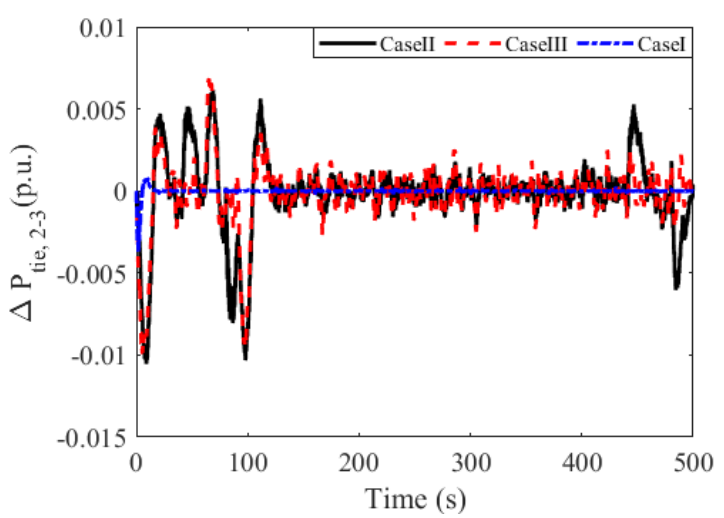

(c)

Fig. 9: Dynamic response of the tie line exchanges among all the three areas represented in (a) between area 1 and 2 (b) between area 1 and 3 and (c) between area 2 and 3 respectively.

\section{ACKNOWLEDGMENT}

This work has been partly supported by the m2M-GRID project of the joint programming initiative ERA-Net Smart Grids Plus.

\section{REFERENCES}

[1] K. Kaur, R. Rana, N. Kumar, M. Singh and and S. Mishra, "A Colored Petri Net Based Frequency Support Scheme Using Fleet of Electric 


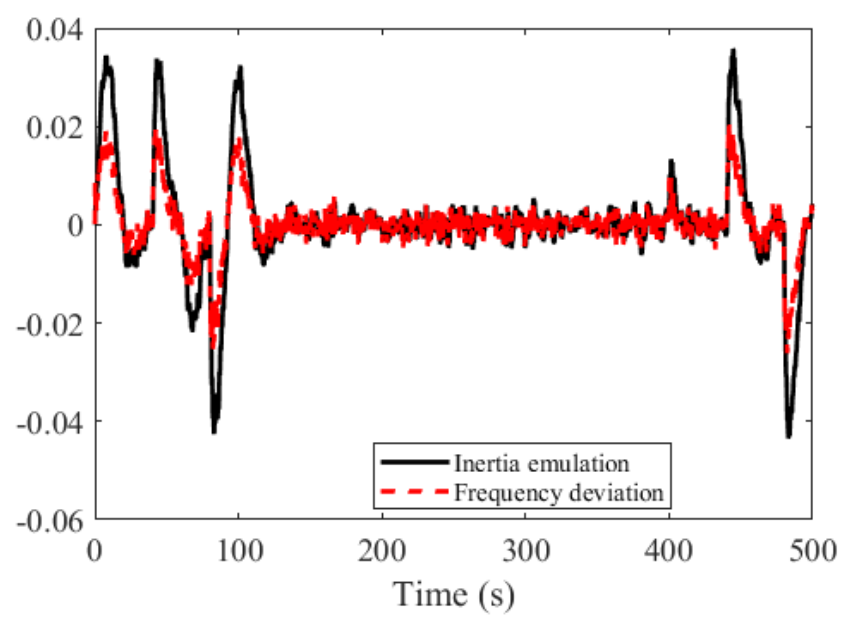

Fig. 10: IE following the deviation in frequency.

Vehicles in Smart Grid Environment", IEEE Transactions on Power Systems, vol. 31, no. 6, Nov. 2016, pp. 46384649.

[2] L. M. Castro, E. Acha, "On the Provision of Frequency Regulation in Low Inertia AC Grids Using HVDC Systems", IEEE Trans. Smart Grid., vol.7, no.6, pp. 2680-2690.

[3] A. Yogarathinam, J. Kaur, N.R. Chaudhuri, "Impact of Inertia and Effective Short Circuit Ratio on Control of Frequency in Weak Grids Interfacing LCC-HVDC and DFIG-based Wind Farms", IEEE Trans. Power Delivery, vol. 32, no. 4, pp. 20402051.

[4] J. Zhu, J. M. Guerrero, W. Hung, C. D. Booth, G. P. Adam, "Generic inertia emulation controller for multi-terminal voltage-source-converter high voltage direct current systems", IET Renewable Power Generation, vol. 8, No. 7, pp. 740-748.

[5] E. Rakhshania, D. Remon, A.M. Cantarellasa, J. M. Garcia, P. Rodriguez, "Modeling and sensitivity analyses of VSP based virtual inertia controller in HVDC links of interconnected power systems", Elec. Power Syst. Res., vol. 141, pp. 246-263, 2016.

[6] E. Rakhshania, D. Remon, A.M. Cantarellasa, P. Rodriguez, "Analysis of derivative control based virtual inertia in multi-area high-voltage direct current interconnected power systems", IET Generation, Transmission and Distribution, vol. 10, no. 6, pp. 1458-1469.

[7] E. Rakhshania, D. Remon, A.M. Cantarellasa, J. M. Garcia, P. Rodriguez, "Virtual Synchronous Power Strategy for Multiple HVDC Interconnections of Multi-Area AGC Power Systems", IEEE Trans. Power Syst., vol. 32. no.3, pp. 16651677.

[8] J. R. Pillai and B. Bak-Jensen, "Integration of vehicle-to-grid in the western Danish power system", IEEE Trans. Sustain. Energy, vol. 2, no.1, pp. 1219, Jan. 2011.

[9] H. Liu, Z. Hu, Y Song, J. Wang, X. Xie, "Vehicle-to-Grid Control for Supplementary Frequency Regulation Considering Charging Demands", IEEE Trans. Power Syst., vol. 30, no. 6, pp. 31103119, Nov 2015.

[10] S. Debbarma, L. C. Saikia and N. Sinha, "AGC of a multi-area thermal system under deregulated environment using a non-integer controller", Elec. Power Syst. Res., vol. 95, 2013, pp. 175-183.

[11] S. Debbarma, L. C Saikia, N. Sinha, "Automatic generation control using two degree of freedom fractional order PID controller", Int. J. of elect. Power energy syst., vol. 58, pp. 120-129, 2014.

[12] C.S.A. Nandar, "Robust PI control of smart controllable load for frequency stabilization of microgrid power system", Renewable Energy, vol. 56, pp. 16-23, 2013.

[13] T.S. Bhatti, A.A.F Al-Ademi, N.K. Bansal, "Load frequency control of isolated wind diesel hybrid power systems", Energy Convers Management Systems, vol. 38, pp. 829-837, 1997.

[14] Dharmakeerthi, C. H., N. Mithulananthan, and T. K. Saha. "Impact of electric vehicle fast charging on power system voltage stability." International Journal of Electrical Power and Energy Systems 57 (2014): 241-249.

[15] Clement-Nyns, Kristien, Edwin Haesen, and Johan Driesen. "The impact of charging plug-in hybrid electric vehicles on a residential distribution grid." IEEE Transactions on power systems 25.1 (2010): 371-380.

[16] Kempker, Pia L., et al. "Smart charging of electric vehicles." Markov Decision Processes in Practice. Springer, Cham, 2017. 387-404.

[17] P. Rodriguez, "Synchronous power controller of a generation system based on static power converters", Patent Number: WO 2012/117131, Priority date: 28 Feb. 2011

[18] P. Dash, L.C Saikia and N. Sinha, "Comparison of performances of several Cuckoo search algorithm based 2DOF controllers in AGC of multi-area thermal system", Int. J. of elect. Power energy syst., vol. 55, pp. 429436, 2014

[19] Vo.N Dieu, P. Schegner, W. Ongsakul, Cuckoo search algorithm for non-convex economic dispatch, IET Generation, Transmission and Distribution, vol. 7, no. 6, pp. 645654, Feb. 2013. 